\title{
Trabalho, terra e geração de renda em três décadas de reflorestamentos no alto Jequitinhonha ${ }^{1}$
}

\author{
Juliana Sena Calixto ${ }^{2}$ \\ Eduardo Magalhães Ribeiro ${ }^{3}$ \\ Flávia Maria Galizoni ${ }^{4}$ \\ Renato Luís Grisi Macedo 5
}

\begin{abstract}
Resumo: A partir dos anos 1970, as chapadas do Alto Jequitinhonha, localizadas no nordeste de Minas Gerais, até então áreas de uso comum de agricultores familiares, foram plantadas com eucaliptos. O objetivo deste artigo é comparar os efeitos do reflorestamento sobre a estrutura fundiária, valor da produção agrícola e ocupação rural com os efeitos da produção agrícola familiar sobre essas mesmas variáveis na microrregião homogênea de Capelinha, no Alto Jequitinhonha. Tal microrregião foi escolhida para o estudo por ser a área de maior concentração de eucaliptais da região. Foram utilizados dados secundários dos Censos do IBGE para os anos de 1970, 1980, 1985 e 1996, além de dados secundários de pesquisas realizadas sobre a região em questão, incluindo entrevistas com dirigentes de empresas e lideranças sindicais. $\mathrm{O}$ artigo conclui que, em trinta anos, o reflorestamento concentrou terras e criou um número reduzido de empregos; a agricultura familiar, ao contrário, teve suas áreas de terras comprimidas e super-exploradas em decorrência da perda das chapadas, mas continuou sendo a principal responsável pela geração de ocupações e rendas na região.
\end{abstract}

\footnotetext{
${ }^{1}$ Este artigo recebeu apoios do CNPq (504.111/03-5 e 504.665/04-9) e da Fapemig (SHA 941/2).

2 Engenheira Florestal, mestre PPGAD/UFLA (bolsista Capes), Analista Ambiental da Superintendência Regional de Meio Ambiente e Desenvolvimento Sustentável do Sul de Minas Gerais; juliana.calixto@yahoo.com.br.

${ }^{3}$ Economista, professor associado da Universidade Federal de Lavras, pesquisador CNPq; eduardomr@ufla.br.

${ }^{4}$ Antropóloga, professora adjunta do ICA/Universidade Federal de Minas Gerais; flaviagalizoni@yahoo.com.br

${ }^{5}$ Engenheiro Florestal, professor da Universidade Federal de Lavras; grisi@ufla.br
} 
Palavras-chave: agricultura familiar; reflorestamentos; emprego rural; desenvolvimento rural; Jequitinhonha.

\begin{abstract}
Beginning in the 1970's the plateaus of Alto Jequitinhonha, northeast of Minas Gerais, until then areas of common use by family farmers, were planted with eucalyptus. This article analyzes the effects of reforestation on land occupation, comparing it with the areas of the family production. It is carried out in the homogenous micro-region of Capelinha, an area with the largest concentration of eucalyptus in the region. Secondary data from the IBGE Census for the years 1970, 1980, 1985 and 1996 were used, and also secondary data from surveys conducted around the region studied, including interviews with management of companies and union leadership. The article concludes that, in thirty years, the reforestation concentrated the land and created reduced employment. Family agriculture, on the other hand, had their areas of land compressed and overexploited due to the loss of the plateaus; however they remained as the main employment and income generator in the area.
\end{abstract}

Key-words: family agriculture; reforestation; rural development; rural employment; Jequitinhonha

Classificação JEL: J21, 013, Q18

\title{
1. Introdução
}

No início do século XIX, o botânico francês Auguste de Saint-Hilaire viajou pelo Jequitinhonha para conhecer a produção de ouro do vale do Araçuaí, as gemas do Distrito Diamantino, as florestas e os índios do baixo rio. A descrição que o botânico legou esboçava a imagem que a posteridade tornaria definitiva: uma região contraditoriamente marcada pela riqueza e pela escassez. No Jequitinhonha contrastavam a abundância de recursos e a luta por alimentos, a exuberância natural e o barbarismo dos colonos, a vitalidade das florestas e a tristeza dos campos maninhos das chapadas. Estes, em particular, o autor lamentava: a paisagem imutável, a amplitude dos horizontes, o ataque sem trégua dos mosquitos, as queimadas que a partir de agosto tingiam o horizonte com o cinzento da fumaça e transformavam o chapadão num deserto que subsistiria até a chegada das chuvas-dos-brotos em setembro, proporcionando vida nova aos cerrados. Saint-Hilaire reclamava do despropósito das chapadas, que, imprestáveis, sequer forneciam boas coletas ao botânico.

Na década de 1970, quase dois séculos depois da viagem de Saint-Hilaire, essas chapadas foram transformadas em florestas de eucaliptos. As empresas reflorestadoras afirmam que eucalipto gera emprego, renda e riqueza para os municípios; mas elas são alvo de críticas que partem de populações rurais, de organizações ambientalistas e sindicais da região, as quais consideram negativos seus resultados sociais e ambientais. 
Quando foram implantados, os eucaliptais eram apresentados como solução para a estagnação econômica persistente da "área problema" , o "vale da miséria", o "vale da morte", como então se dizia. Após trinta anos, com meio milhão de hectares plantados, o Jequitinhonha continua sendo um exemplo negativo em meio às regiões agrícolas do País; para programas públicos ainda é um problema a ser resolvido, prioridade para todos os governos, alvo de programas compensatórios de combate à fome e à pobreza. No entanto, muitos pesquisadores e formuladores de políticas asseguram que a região deve continuar a receber os plantios de eucaliptos; seria, já, uma "vocação".

Este artigo analisa aspectos sócio-econômicos dos eucaliptais na Microrregião Homogênea de Capelinha (MRH 31011/IBGE), que até 1997 era formada pelos municípios de Berilo, Capelinha, Carbonita, Chapada do Norte, Francisco Badaró, Itamarandiba, Minas Novas e Turmalina. Esta MRH foi analisada por abrigar a maior área rural plantada com eucaliptos do Jequitinhonha em termos percentuais, por conta do ativo movimento sindical e ambiental que há alguns anos associa os eucaliptais aos problemas da região e, finalmente, por nela predominar as características costumeiramente associadas à região: pequena unidade familiar, forte cultura local, expressiva animação comunitária e migração sazonal. Certamente que reflorestamentos envolvem aspectos sociais, econômicos e ambientais. Mas o artigo privilegia apenas os primeiros porque geralmente se argumenta que eventuais impactos ambientais seriam compensados pelos benefícios sociais criados. E como a pequena produção familiar permaneceu no rural da região, o artigo compara eucaliptais com produção familiar não integrada, no propósito de contribuir na seleção de atividades prioritárias para programas de desenvolvimento regional.

O artigo está organizado em cinco partes além desta introdução. A segunda parte descreve a metodologia usada; a terceira seção apresenta o processo que justificou a implantação dos eucaliptais; na quarta parte são expostos os resultados da pesquisa e, por fim, a quinta parte faz um balanço sintético das contribuições dos diferentes sistemas produtivos.

\section{Metodologia}

A partir de 1960 foram realizadas pesquisas, escritos artigos e relatórios sobre o Vale do Jequitinhonha, pois desde então a região se tornou alvo de programas públicos e objeto de estudos para o planejamento, realizados principalmente por agências governamentais. Depois das décadas de 1970/1980 foram feitos estudos, principalmente acadêmicos, que testemunharam a implantação dos eucaliptais, acompanharam sua evolução e analisaram suas relações com a agricultura de pequena escala e as migrações sazonais; são, sobretudo, estudos qualitativos. Esta bibliografia consolidada, em parte, lastreou este artigo. 
Mas dado o caráter polêmico e, definitivamente político da questão da terra e da monocultura de eucaliptos na região, o artigo foi baseado em dados estáveis e, principalmente, comparáveis. Por isto os Censos do IBGE dos anos de 1970, 1980, 1985 e 1996 foram usados como fontes de informação para quantificar atividades agrícolas, população e ocupação.

Produto, renda, ocupação e uso da terra para eucaliptais e agricultura familiar foram calculados a partir do Censo Agropecuário de 1996 que, além de ser o mais recente, apresenta maior detalhamento que os anteriores. Para analisar a agricultura familiar foi, ainda, utilizada a base de dados FAO/Incra, resultado de tabulações avançadas do Censo Agropecuário de 1996. Para fazer comparações entre ocupações criadas por diferentes atividades agrícolas foram usadas as matrizes de emprego rural da Fundação Sistema Estadual de Análise de Dados (SEADE/SP) e o Î́ndice de Gini foi empregado para analisar a evolução dos níveis de concentração da terra.

Para contornar a ausência de dados censitários depois de 1996 foram usados estudos recentes sobre a região, dados de empresas, órgãos públicos e agências privadas. Informações sobre área plantada, salários e produção foram obtidas por meio de entrevistas com dirigentes das principais empresas que atuam na região: CAF, Florestal Acesita e Suzano. O cálculo de renda familiar foi baseado em pesquisas dos anos 2000 e entrevistas com dirigentes sindicais.

Embora as informações censitárias e não censitárias sejam convergentes, o artigo não pôde realizar uma evolução histórica completa dos eucaliptais e da agricultura familiar na MRH usando a mesma base de dados até 2000. A ocupação na agricultura familiar no ano de 2005 teve que ser atualizada com base na projeção da taxa de urbanização verificada na região entre os Censos Demográficos de 1970 e 2001, que revelou queda média de $14 \%$ de residentes no meio rural a cada dez anos. Dificuldades semelhantes ocorreram na atualização de dados das reflorestadoras. Foi necessário recorrer às informações das três maiores empresas (Suzano, Acesita e CAF), responsáveis por 95\% da área plantada da $\mathrm{MRH}$, o que conduziu a uma pequena subestimação do produto e da renda dos reflorestamentos para 2005, por excluir as empresas de menor porte. É verdade que esses ajustes representam limitações, mas elas se impuseram em face da ausência de dados censitários.

Para calcular ocupação e valor da produção nos eucaliptais foi computada toda a área apropriada pelas empresas, e não apenas a área reflorestada, pois o que se buscava era avaliar a eficiência na ocupação de área. Ressalte-se que para analisar as formas de uso do solo pela agricultura familiar foi usado o mesmo procedimento, não distinguindo área manejada na área total. Considera-se também que todo o plantio de eucalipto tem como fim a produção de carvão vegetal, e que toda a contratação de pessoal em silvicultura é feita pelas reflorestadoras.

Por último, é necessário esclarecer que a renda anual do trabalho foi calculada considerando os valores históricos dos salários mínimos vigentes em maio de cada ano. 


\section{Revisão bibliográfica: reflorestamentos no Alto Jequitinhonha}

Foi o estado que estimulou o plantio de eucaliptos no Jequitinhonha. Os governos militares (1964-1985) consideravam a siderurgia um setor estratégico, por conta da expansão da demanda por aço associada ao crescimento industrial. Isto levou à formulação de planos para o setor, que eram limitados pela escassez de carvão, mineral ou vegetal, e desde 1960 foram criados programas de apoio ao reflorestamento em Minas Gerais, principal pólo siderúrgico movido à carvão vegetal do País. Os defensores das florestas de eucalipto argumentavam pelo esgotamento da mata atlântica, pela "desocupação" das terras dos cerrados e pela produtividade dos eucaliptais, pois o primeiro corte acontecia aos 7 anos e o rendimento atingia 111 metros cúbicos de carvão por hectare. Era considerada, ainda, a pesquisa científica já consolidada sobre o cultivo da espécie no País (Faria, 1971; Borges e Colombaroli, 1978; Coutinho, 1985, Calixto, 2006).

Por isso, os eucaliptais foram apoiados com incentivos fiscais que concediam às pessoas físicas e jurídicas descontos de até $50 \%$ no imposto de renda para aplicação em projetos próprios ou de terceiros. Essa medida estimulou investidores: as pessoas físicas recebiam empréstimos para investir, pessoas jurídicas podiam abater os investimentos dos impostos antes mesmo de executar os projetos. No período de 1966 a 1986, os subsídios para reflorestamentos montaram, em média, $\mathrm{R} \$ 2.112,00$ por hectare plantado, em reais de 1998 (Bacha e Barros, 2004; Calixto, 2006).

Além disso, o governo de Minas Gerais ofereceu incentivos específicos para o reflorestamento, principalmente terras, e criou os Distritos Florestais, regiões prioritárias para implantação de florestas. Um deles foi localizado no Jequitinhonha, então considerado um "bolsão de pobreza". O propósito era integrá-lo ao padrão de crescimento do estado usando este e outros programas para "o incremento da renda e do emprego através do incentivo, da coordenação e do planejamento florestal (...)" (Minas Gerais, 1971; IEF, 1975:25).

O Distrito Florestal do Vale do Jequitinhonha praticamente se restringiu ao Alto Jequitinhonha, região caracterizada pela presença de pequenas unidades rurais de produção, onde predominam trabalho e gestão familiar, organizada em comunidades rurais que têm em comum o parentesco, a cultura e o sentimento de pertencimento àquele território. São sítios, localizados no fundo das grotas - as partes baixas do relevo, próximas às margens dos rios, de solos férteis - que empregam sistemas produtivos que dependem em quase tudo da natureza. Nas grotas são feitos os cultivos de mantimentos para consumo direto e comercialização que, na maioria das vezes, é feita em feiras livres. Grotas se opõem e, ao mesmo tempo, complementam as chapadas, que são áreas altas, planas e de baixa fertilidade, mas abundantes em recursos naturais. A 
complementaridade grota-chapada impõe a descontinuidade de áreas produtivas e a agricultura familiar tradicional da região ajusta a produção à disponibilidade de recursos naturais, usando técnicas baseadas no conhecimento que desenvolveu no convívio com a natureza. ${ }^{6}$

Até 1970 essas comunidades rurais partilhavam as terras de grotas para uso privativo de cada família e usavam em comum as chapadas para coleta de frutaspequi, jatobá, mangaba e jacas -, para "solta" dos animais que se criavam "alongados" por léguas e para coleta das plantas medicinais, ornamentais, lenha e madeira para usos especializados, como cinza para decoada, cangas de bois e peças para engenhos. Por conta desta coleta difusa, o domínio das terras de chapadas era impreciso, regulado por direitos frágeis e compartilhados, que dificilmente eram compreendidos na noção de "propriedade" que se exercia de forma plena apenas nos terrenos férteis das grotas. A chapada era de ninguém e de todos, uma terra "coletiva, costumeira e indivisa". As comunidades rurais regulavam o uso dos recursos naturais disponíveis e foi justamente a gestão comunitária que os conservou até $1970 .{ }^{7}$

Para formuladores de programas públicos, esse domínio costumeiro da terra equivalia à ausência de ocupação e uso: era um "vazio", conforme se definiu na época, e sua privatização foi estimulada. Consideradas áreas devolutas, pertencentes ao Estado, foram transferidas para as reflorestadoras atraídas para a região, como a então estatal Acesita Florestal, a Companhia Agrícola e Florestal Santa Bárbara (CAF), empresa da Companhia Siderúrgica Belgo-Mineira, e a Companhia Suzano, além de empreiteiras dessas e de outras empresas.

A privatização das chapadas homogeneizou a paisagem, reduziu a biodiversidade do cerrado, destruiu habitats para da fauna, elevou a pressão sobre os recursos hídricos, além de expropriar lavradores que perderam grande parte das áreas de terras em comum. Esses prejuízos derivados dos eucaliptais seriam compensados pelo progresso e pela geração de emprego e renda que, se supunha, as atividades tradicionais jamais criariam.

${ }^{6}$ O Vale do Jequitinhonha abrange áreas de Minas Gerais e Bahia com características históricas, ambientais e econômicas diferentes; para uma distinção entre elas consultar Ribeiro e Galizoni (2000); sobre o Alto Jequitinhonha ver estudos de Graziano (1986), Moura (1988), além de Ribeiro e Galizoni (2000).

${ }^{7}$ A citação é de Moura (1988: 36); a terra de todos é referência a Thompson (1998:132) sobre commoners ingleses: "A terra pertencia em geral a todo mundo, mas em particular a ninguém". Furtado (1985), Graziano (1986) e Moura (1988) estudaram a ocupação dessas terras; consultar também Galizoni (2002) e Ribeiro e outros (2006). Sobre usos de recursos naturais e agricultura tradicional na região ver Dayrell (1998) e Calixto (2002). 


\section{Resultados}

\subsection{Transformações na terra e na ocupação}

Os eucaliptais provocaram notáveis mudanças no uso da terra na MRH de Capelinha. A Tabela 1 compara as áreas utilizadas para silvicultura, agricultura e pecuária ao longo de três décadas.

Tabela 1. Utilização das terras na MRH Capelinha, de 1970 a 1995, em hectares.

\begin{tabular}{lcccc}
\hline \multirow{2}{*}{ Categoria } & \multicolumn{4}{c}{ Ano } \\
\cline { 2 - 5 } & $\mathbf{1 9 7 0}$ & $\mathbf{1 9 8 0}$ & $\mathbf{1 9 8 5}$ & $\mathbf{1 9 9 5}$ \\
\hline Florestas plantadas & 222 & 131.030 & 105.747 & 158.124 \\
Pastagens plantadas & 18.590 & 29.178 & 52.130 & 72.678 \\
Lavouras permanentes & 2.128 & 13.281 & 27.771 & 16.218 \\
Lavouras temporárias, em & 46.606 & 85.357 & 98.031 & 44.344 \\
produção ou descanso & 69.983 & 147.573 & 158.980 & 66.193 \\
Pastagens naturais & 137.529 & 406.419 & 442.659 & 357.557 \\
Total de área declarada & & & &
\end{tabular}

Fontes: FIBGE, Censos 1970, 1980, 1985 e 1996.

A Tabela 1 indica que ocorreu um elevado crescimento nas áreas de florestas plantadas. Embora se verifique um hiato entre 1980 e 1985, ao longo do tempo percebe-se a expansão concentrada entre 1970 e 1980, período de abundância dos incentivos fiscais. Houve também aumento nas áreas de pastagens plantadas ao longo de todo o período; foi originado em grande parte pela introdução do capim braquiária (Brachiaria decumbens) a partir de 1970, e assinala uma tendência firme de pecuarização na MRH. Sindicalistas e mediadores têm associado o crescimento das áreas de pastagens plantadas à redução das áreas de soltas nas chapadas, o que forçou a intensificação da criação animal nas terras mais férteis das grotas. Ocorreu também aumento na área de lavouras permanentes, principalmente entre 1970 e 1985, associado à adoção de novas técnicas de cultivo agrícola dos campos e aos incentivos governamentais para implantação do café na região. Mas se verifica que entre 1970 e 1995 houve redução nas áreas de lavouras temporárias - principal atividade nas pequenas unidades familiares de produção-embora tenha se verificado crescimento entre 1970/1980 e 1980/1985. ${ }^{8}$

Ao longo do período 1970/1995, o crescimento de áreas de lavouras permanentes, pastagens e florestas plantadas contrasta com a estabilização das

${ }^{8}$ Sobre os incentivos à cafeicultura na região ver Graziano (1986) e Nunes (2001). A expansão de atividades relacionadas à agricultura familiar na década de 1980 foi associada às migrações de retorno ou à redução das migrações definitivas, em conseqüência da recessão do início desta década; consultar sobre o assunto Ribeiro e Carvalho (1999). 
áreas de lavouras temporárias e pastagens naturais. Os usos da terra que expandiram são associados à capitalização da produção; os usos estabilizados lavouras temporárias e pastagens naturais - são relacionados aos manejos tradicionais da terra feitos pela agricultura familiar. Percebe-se que há mudança, mas também persistência, e assim se configura uma estrutura produtiva dual, segmentada em atividades mais e menos intensivas em capital.

A Tabela 2 mostra a distribuição fundiária na MRH de Capelinha entre 1970 e 1995. Os dados indicam que até a década de 1970 havia uma distribuição fundiária razoavelmente eqüitativa, sendo a maioria da área ocupada de pequenos estabelecimentos rurais. Em 1995, as pequenas unidades rurais familiares, com menos de 100 hectares, continuaram sendo maioria dos estabelecimentos; mas, nestes 25 anos, a área que ocupavam caiu menos da metade. Também decresceu a área ocupada por estabelecimentos médios, de 101 a 1.000 hectares. Inversamente, no período, cresceu quase dez vezes a área ocupada por estabelecimentos maiores que 1.000 hectares; no caso, fundamentalmente por empresas reflorestadoras. Mas como os eucaliptais se fixaram mais em alguns municípios da $\mathrm{MRH}$, seus efeitos fundiários foram desiguais. Municípios com menos de 10\% de área total reflorestada conservaram distribuição semelhante àquela dos anos 1970; resultado diverso ocorreu nos municípios com maiores áreas reflorestadas, onde a concentração fundiária foi mais ativa, como na Tabela 2.

Tabela 2. Distribuição fundiária na MRH de Capelinha, 1970 e 1995, em percentual.

\begin{tabular}{llcccccc}
\hline \multirow{2}{*}{ Ano } & $\begin{array}{l}\text { Grupos de } \\
\text { área total } \\
\text { (hectares) }\end{array}$ & \multicolumn{2}{c}{ MRH } & \multicolumn{3}{c}{$\begin{array}{c}\text { Municípios } \\
\text { com mais } \\
\text { reflorestamento }\end{array}$} & \multicolumn{3}{c}{$\begin{array}{c}\text { Municípios } \\
\text { com menos } \\
\text { reflorestamento }\end{array}$} \\
\cline { 2 - 8 } & & $\begin{array}{l}\text { Estabele- } \\
\text { cimentos }\end{array}$ & Área & $\begin{array}{l}\text { Estabele- } \\
\text { cimentos }\end{array}$ & Área & $\begin{array}{c}\text { Estabele- } \\
\text { cimentos }\end{array}$ & Área \\
\hline \multirow{2}{*}{1970} & Até 100 & 97,72 & 64,95 & 97,23 & 61,95 & 98,62 & 74,01 \\
& 101 a 1.000 & 2,22 & 29,70 & 2,72 & 32,79 & 1,32 & 20,64 \\
& Mais de 1.000 & 0,06 & 5,35 & 0,05 & 5,26 & 0,06 & 5,35 \\
1995 & Até 100 & 96,31 & 31,94 & 95,61 & 25,26 & 97,60 & 65,48 \\
& 101 a 1.000 & 3,48 & 19,88 & 4,12 & 18,59 & 2,32 & 26,41 \\
& Mais de 1.000 & 0,21 & 48,18 & 0,27 & 56,15 & 0,08 & 8,11 \\
\hline
\end{tabular}

Fonte: FIBGE, Censos Agropecuários, 1970 e 1996.

O efeito da monocultura de eucaliptos sobre a terra pode ser analisado também por meio do Índice de Gini, um indicador universal. A Tabela 3 exibe os índices de concentração fundiária entre 1970/1995 para o Brasil, Minas Gerais e a MRH de Capelinha. Até 1970, a MRH apresentava índice médio de concentração, baixa desigualdade no acesso à terra e hegemonia da pequena unidade familiar. 
O reflorestamento promoveu tal concentração que, a partir dos anos 1980, equalizou os indicadores da MRH com o Brasil e Minas Gerais 9 .

Tabela 3. Distribuição fundiária: Índice de Gini para o Brasil, Minas Gerais e MRH de Capelinha de 1970 a 1995.

\begin{tabular}{lcccc}
\hline \multirow{2}{*}{ Unidade territorial } & \multicolumn{5}{c}{ Ano } \\
\cline { 2 - 5 } & $\mathbf{1 9 7 0}$ & $\mathbf{1 9 8 0}$ & $\mathbf{1 9 8 5}$ & $\mathbf{1 9 9 5}$ \\
\hline Brasil & 0,843 & 0,857 & 0,857 & 0,856 \\
Minas Gerais & 0,749 & 0,766 & 0,770 & 0,772 \\
MRH de Capelinha & 0,301 & 0,757 & 0,734 & 0,764 \\
\hline
\end{tabular}

Fontes: Gasques e Conceição (1998); FIBGE, Censos; cálculo dos autores.

No período também ocorreram mudanças qualitativas e quantitativas na ocupação de força de trabalho, conforme a Tabela 4 . O número de ocupações na agropecuária ao longo das três décadas declinou $28,48 \%$ - no período, o declínio médio no Brasil foi de 23\% (FIBGE, 1996). Ocorreu pequeno crescimento no número de empregados permanentes, redução no número de ocupações no trabalho familiar, mas a expansão de um não compensou o declínio de outro, e o perfil da ocupação regional permaneceu quase o mesmo: um rural marcado pelo trabalho familiar com presença esparsa do assalariamento.

Tabela 4. Pessoal ocupado na agropecuária, por categoria, na MRH Capelinha entre 1970 e 1995 em números absolutos e relativos.

\begin{tabular}{|c|c|c|c|c|c|c|c|c|c|}
\hline \multirow{2}{*}{ Categoria } & \multicolumn{2}{|c|}{1970} & \multicolumn{2}{|c|}{1980} & \multicolumn{2}{|c|}{1985} & \multicolumn{2}{|c|}{1995} & \multirow{2}{*}{$\begin{array}{c}1970 / \\
1995 \\
(\%) \\
\end{array}$} \\
\hline & Total & $\%$ & Total & $\%$ & Total & $\%$ & Total & $\%$ & \\
\hline RMNRF 1 & 60.956 & 86,47 & 62.266 & 74,56 & 70.659 & 84,73 & 41.600 & 82,51 & $-31,75$ \\
\hline $\begin{array}{l}\text { Empregados } \\
\text { permanentes }\end{array}$ & 648 & 0,92 & 3.687 & 4,42 & 3.528 & 4,23 & 2.762 & 5,48 & 326,23 \\
\hline $\begin{array}{l}\text { Empregados } \\
\text { temporários }\end{array}$ & 6.933 & 9,83 & 16.437 & 19,68 & 8.508 & 10,20 & 5.273 & 10,46 & $-23,94$ \\
\hline Outros & 1.954 & 2,78 & 1.118 & 1,34 & 700 & 0,84 & 781 & 1,55 & $-60,03$ \\
\hline Total & 70.491 & 100,00 & 83.508 & 100,00 & 83.395 & 100,00 & 50.416 & 100,00 & $-28,48$ \\
\hline
\end{tabular}

O efeito incremental dos eucaliptais sobre o emprego ficou concentrado no período 1970/1980, no auge do plantio, quando cresceu a demanda por trabalho braçal na cata de raízes e formação de viveiros; mas a categoria dos empregados

9 Os graus de concentração do Índice são: Nula: 0,000 a 0,100; Fraca: 0,101 a 0,250; Média: 0,251 a 0,500; Forte: 0,501 a 0,700; Muito forte: 0,701 a 0,900; Absoluta: 0,901 a 1,000 (Linhares \& Teixeira de Silva, 1999). 
temporários declinou nos anos seguintes, revelando a precariedade da expansão. A categoria "responsáveis e membros não remunerados da família" (RMNRF), composta basicamente pelo trabalho não assalariado na pequena unidade produtiva familiar, permaneceu ao longo das três décadas respondendo por nível de ocupação sempre superior a 70\% do pessoal. O Censo de 1996 revelou ainda que, dos 2.762 empregados permanentes - supostamente a principal categoria empregada pelos eucaliptais -, apenas $1.612(58,36 \%)$ estavam ocupados em silvicultura e que a maioria do emprego temporário era oferecido pela lavoura permanente - basicamente a cafeicultura - e pela pecuária, atividade tradicional da região.

Em 1995, a área ocupada com eucaliptais na MRH totalizava 158.124 hectares e a silvicultura empregava 1.768 trabalhadores permanentes. Eram necessários 89,44 hectares plantados em eucaliptos para criar um emprego permanente e, dominando $28,11 \%$ da área rural, a silvicultura não revelara capacidade para incrementar os empregos, pois respondia por apenas 3,78\% do total das ocupações. Essa taxa média de ocupação por hectare, aliás, está muito próxima de outras médias regionais: estudos para o estado de São Paulo apontam que a silvicultura ocupava, em média, um trabalhador para 100 hectares em nível tecnológico alto e um trabalhador para 90,91 hectares em níveis tecnológicos médio e baixo (Fundação SEADE, 1996); no Sul da Bahia, os eucaliptais ainda em fase de expansão criam uma ocupação para cada 69,30 hectares plantados (Koopmans, 2006).

\subsection{Os eucaliptais nos anos 2000}

O carvoejamento costuma ser uma atividade cíclica: existem períodos de exploração mais e menos intensa, determinados por demandas do mercado externo, variação cambial, preço relativo do coque, demanda interna por ferro-gusa, entre outros fatores. Como 1995 foi um período de baixa no ciclo da atividade carvoeira, foram calculados o uso da terra e da ocupação nos eucaliptais também para 2005, usando informações não-censitárias, fornecidas pelas principais empresas. $\mathrm{O}$ ano de 2005 foi excepcionalmente positivo para a silvicultura, pois os preços do carvão vegetal apresentaram uma variação nominal de 130\% entre 2001/2005 (AMS, 2005).

As principais etapas da cultura do eucalipto são a produção de mudas, preparo da terra, plantio, tratos culturais, colheita e transporte. São necessários ainda o corte da lenha, carga nos fornos, carbonização, descarregamento dos fornos e transporte para fabricar carvão vegetal. As atividades que mais possuem trabalhadores são a produção de mudas, o plantio e a colheita, sendo os tratos culturais menos intensivos em relação à ocupação. $\mathrm{O}$ aumento da mecanização nas empresas reflorestadoras leva à redução da demanda por pessoal em todas as atividades. Por isso, as maiores empresas que atuam na MRH foram 
hierarquizadas em dois níveis, determinados pelo padrão tecnológico: Acesita (Grupo Acelor), mecanização intensiva e alto nível tecnológico; CAF (Grupo Acelor) e Suzano, que realizam corte com moto-serra e carvoejamento manual nível tecnológico médio. Dados dessas três principais companhias estão na Tabela 5, ressalvando-se mais uma vez que essas informações referem-se apenas a elas; dados dos Censos abrangem toda a silvicultura da MRH.

Tabela 5. Produção e ocupação de empresas silvicultoras de grande porte na MRH Capelinha em 2005.

\begin{tabular}{lccccc}
\hline $\begin{array}{l}\text { Empresa e nível } \\
\text { tecnológico }\end{array}$ & $\begin{array}{c}\text { Produção } \\
\text { de carvão } \\
\text { (m³/ano) }\end{array}$ & $\begin{array}{c}\text { Área } \\
\text { plantada } \\
\text { (ha) }\end{array}$ & $\begin{array}{c}\text { Produtividade } \\
\text { (m3/ha/ano) }\end{array}$ & $\begin{array}{c}\text { Pessoal } \\
\text { ocupado }\end{array}$ & $\begin{array}{c}\text { Área requerida } \\
\text { para criar uma } \\
\text { ocupação (ha) }\end{array}$ \\
\hline Acesita (Alto) & 720.000 & 126.000 & 5,71 & 1.008 & 125,00 \\
CAF (Médio) & 120.000 & 41.000 & 2,93 & 492 & 83,33 \\
Suzano (Médio) & 255.944 & 51.000 & 5,02 & 630 & 83,33 \\
Totais & 1.095 .944 & 218.000 & 5,03 & 2.130 & 102,35 \\
\hline
\end{tabular}

Fonte: Informações fornecidas pelas empresas, em 2005; cálculos dos autores.

Os dados da Tabela 5 indicam relação direta entre nível tecnológico e demanda por trabalho na silvicultura, pois as duas empresas de menor sofisticação tecnológica apresentam maior taxa de ocupação. Observe-se que a taxa de ocupação por hectare no nível tecnológico médio é quase a mesma revelada pelos dados censitários de 1996. Percebe-se, também pelas fontes das empresas, que grandes plantios de eucaliptos geram número muito reduzido de ocupações. A Tabela 5 permite antever a queda que sofrerá a ocupação na silvicultura da MRH se as empresas cumprirem o objetivo de ampliar a mecanização das atividades produtivas, conforme depoimentos dos seus representantes; o incremento tecnológico fatalmente eliminará empregos.

O principal produto dos eucaliptais desta MRH é o carvão, que internaliza renda nos municípios onde é produzido, principalmente por meio dos salários e do Imposto sobre Circulação de Mercadorias e Serviços (ICMS). Este corresponde a 3\% do Valor Bruto da Produção (VBP), do qual 25\% (ou 0,75\% do Valor tarifado) retornam aos municípios. Dispondo do volume de carvão produzido é possível estimar o VBP para 1995 e 2005. Em 1995 (Censo 1996), a produção vendida pela silvicultura na MRH foi de 120.000 toneladas, ou $342.857,14 \mathrm{~m}^{3}$ de carvão vegetal, totalizando R\$20.993.000,00 a preços históricos. Para 2005, segundo dados da produção das três maiores empresas, o VBP atingiu R $\$$ 89.455.330,00.

Essas informações sobre a silvicultura estão consolidadas na Tabela 6, lembrando que os dados de 2005 são mais limitados que aqueles de 1995, de origem censitária. 
Trabalho, terra e geração de renda em três décadas de reflorestamentos no alto Jequitinhonha

Tabela 6. Dados consolidados sobre silvicultura na MRH Capelinha em 1995 e 2005

\begin{tabular}{lcccccc}
\hline Ano & $\begin{array}{c}\text { Ocupações } \\
\text { permanentes }\end{array}$ & Área (ha) & $\begin{array}{c}\text { Hectares } \\
\text { requeridos } \\
\text { para criar } \\
\text { ocupação }\end{array}$ & $\begin{array}{c}\text { Produção de } \\
\text { carvão } \\
\left(\mathbf{m}^{3} / \mathbf{a n o}\right)\end{array}$ & $\begin{array}{c}\text { Valor da } \\
\text { produção } \\
\mathbf{( R \mathbf { 1 0 0 0 } )}\end{array}$ & VBP/ha (R\$) \\
\hline 1995 & 1.768 & 158.124 & 89,44 & 342.857 & $20.993,00$ & 132,76 \\
2005 & 2.130 & 218.000 & 102,35 & 1.095 .944 & $89.455,33$ & 410,35 \\
\hline
\end{tabular}

Fontes: FIBGE, Censo Agropecuário, 1996; em 2005: entrevistas com empresas; para detalhamento da metodologia consultar Calixto (2006).

Percebe-se na Tabela 6 que, na última década, ocorreu um acréscimo de $20,48 \%$ no emprego gerado, acompanhando incremento de, pelo menos, 37,86\% da área territorial ocupada. Assim, ocorreu queda relativa na ocupação em termos de área utilizada. É preciso ressalvar o caráter conjuntural deste crescimento, pois se observa que a produção de carvão triplicou no período, influenciada pelo movimento ascensional da demanda em 2005, quando os preços do carvão vegetal subiram e aceleraram a carbonização em toda a silvicultura do norte/nordeste de Minas Gerais. Esse foi um ano de produção elevada de carvão, com movimento atípico de preços que foi originado do aumento das exportações de ferro-gusa. Este último estimulou o corte em muitas áreas maduras há tempos e gerou expansão da produção. $\mathrm{O}$ aumento do preço do carvão teve conseqüências na MRH, elevando a produção das empresas que exploraram áreas quase abandonadas por causa da substituição do carvão vegetal pelo coque na siderurgia. Mas o número de ocupações criadas, em termos relativos e absolutos, permaneceu reduzido; a taxa de ocupação por hectare de eucalipto continuou baixa em comparação com outras atividades tradicionais e tende a piorar à medida que as empresas incorporam capital à produção.

\subsection{Agricultura familiar}

Com a expansão dos eucaliptais, a agricultura familiar da MRH ficou restrita praticamente às áreas de grotas, as terras declivosas e drenadas das vertentes das chapadas, onde foram concentrados seus sistemas produtivos.

Agricultores familiares do Alto Jequitinhonha utilizam o sistema de produção que se convenciona denominar tradicional: uma agricultura praticamente independente de insumos externos, pautada pela oferta local de recursos, profundamente relacionada ao ambiente, clima e tipo de solo. A produção requer grande contingente de trabalhadores, principalmente para capina e colheita; suas taxas de ocupação estão apresentadas na Tabela 7. 
Tabela 7. Área, estabelecimentos e ocupação na agricultura familiar na MRH de Capelinha, em 1995.

\begin{tabular}{lcccccc}
\hline Item Área (ha) & $\begin{array}{c}\text { Estabele- } \\
\text { cimentos }\end{array}$ & $\begin{array}{c}\text { Pessoal } \\
\text { ocupado }\end{array}$ & $\begin{array}{c}\text { Área média } \\
\text { (ha) }\end{array}$ & $\begin{array}{c}\text { Ocupação/ } \\
\text { estabele- } \\
\text { cimento }\end{array}$ & $\begin{array}{c}\text { Árequerida } \\
\text { para criar uma } \\
\text { ocupaça (ha) }\end{array}$ \\
\hline Valor & 172.095 & 10.439 & 34.830 & 16,49 & 3,34 & 4,95 \\
\hline \multicolumn{7}{l}{ Fonte: Censo Agropecuário, 1996; tabulações especiais FAO/Incra. }
\end{tabular}

Percebe-se que esta agricultura tem uma elevada capacidade de criar ocupações por hectare de terra apropriado: uma pessoa ocupa cada 4,95 hectares. Considerando que áreas de campos pedregosos equivalem em área às boas terras de cultura, e que apenas estas são agricultáveis, é possível concluir que a ocupação de pessoal por hectare efetivamente produtivo é, ainda, mais intensa que esses dados sugerem. Além disso, é preciso considerar que essa ocupação tem caráter familiar, garantindo ao ocupado acesso simultâneo à terra, ao trabalho e aos seus frutos, dando à ocupação um caráter distributivo, contribuindo para a estabilidade da economia regional ${ }^{10}$.

Os dados do Censo de 1996 revelam que a agricultura familiar em 1995 gerou uma produção cujo valor alcançou $\mathrm{R} \$ 22.719 .000,00$, o que correspondia a 46,48\% do valor da produção agrícola total da MRH (FIBGE, 1996). Há que considerar, ainda, que parte do sustento da agricultura familiar da região vem do extrativismo de frutos, plantas medicinais e produtos do artesanato comercializados nas feiras livres municipais, que não são computados no valor da produção no Censo, mas são importantes para a economia das famílias ${ }^{11}$.

Para estimar o Valor da Produção Bruta da agricultura familiar em 2005 foram necessários cálculos indiretos. Primeiro, foi preciso estimar que ocorreu uma queda na população da área rural no intervalo 1995/2005; avaliou-se em 14\% , com base na taxa média decenal de urbanização verificada na MRH entre 1970/2001. Segundo, foi necessário calcular o VBP da produção agrícola. Uma estimativa conservadora apontou 1,33 salários mínimos mensais por domicílio com 4,5 pessoas, composição média das famílias rurais da MRH (Ribeiro, Castro e Ribeiro, 2004); outra estimativa apontou que a produção de auto-consumo correspondia, em média, a 27,30\% desta renda ou $\mathrm{R} \$ 150,20$ a preços de 2005 (Ribeiro e outros, 2007). Ainda é necessário considerar todo o peso das rendas não agrícolas, pois pesquisas indicam que em cada família rural da MRH há em média 0,62 aposentado ou pensionista (Ribeiro e outros, 2007); estimando-se em 8.977 as famílias rurais da MRH em 2005, conclui-se que existem 5.566 aposentados ou pensionistas rurais. A renda anual de aposentadorias rurais na MRH de Capelinha pode ser estimada em $\mathrm{R} \$ 27.707 .400,00$ para 2005. Por fim, há a

${ }^{10}$ Sobre a relação entre agricultura familiar e estabilidade econômica consultar Veiga (2001).

${ }^{11}$ Sobre extrativismo nesta MRH do alto Jequitinhonha consultar Noronha (2003) e Ribeiro e outros (2005). 
migração sazonal, que também é uma estratégia de complementação da renda para famílias rurais da região, sendo que parte da renda obtida é utilizada para melhoramentos dos sítios, moradias e transporte. Há indicações que 23.220 trabalhadores migram sazonal e anualmente na MRH (Estado de Minas, 05/05/2006); pesquisa de campo indica que cada ciclo migratório representa um saldo médio de 9 salários mínimos per capita; considerando apenas um quarto desses migrantes de origem na agricultura familiar, a renda total internalizada seria de R\$ 15.673.500,00 em 2005.

Produção, aposentadorias e migração conformam a maioria do movimento econômico da agricultura familiar da MRH. Dados sintéticos estão expostos abaixo na Tabela 8.

Tabela 8. Rendas da agricultura familiar na MRH Capelinha, 1995 e 2005.

\begin{tabular}{|c|c|c|c|c|}
\hline Ano & Famílias & Valores por fontes & Valor (R\$) & $\begin{array}{c}\text { Renda familiar } \\
\text { (R\$/ano) }\end{array}$ \\
\hline 1995 & 10.439 & Valor Bruto da Produção & $22.719 .000,00$ & $2.176,36$ \\
\hline \multirow{4}{*}{2005} & \multirow{4}{*}{8.977} & Valor Bruto da Produção & $70.042 .214,40$ & \multirow{4}{*}{$12.634,84$} \\
\hline & & Aposentadorias & $27.707 .400,00$ & \\
\hline & & Migrações & $15.673 .500,00$ & \\
\hline & & Sub-total & $113.423 .114,40$ & \\
\hline
\end{tabular}

Fonte: Censo Agropecuário, 1996; Ribeiro e outros, 2007; MDS, 2005; cálculos dos autores.

\subsection{Monocultura de eucalipto e agricultura familiar: um balanço}

Os dados sobre renda, ocupação de terra e força de trabalho dão bases mesmo que desiguais, dada a diversidade das fontes - para avaliar as duas principais formas de exploração da terra na MRH de Capelinha. A atividade de dimensão social e produtiva mais abrangente continua sendo a agricultura familiar, embora sofra restrições de área agrícola que limitam a produção e parcializam a ocupação. Os dados revelam a importância dessa população tradicional e de seus sistemas produtivos: a produção permanece mesmo em glebas muito limitadas e excedentes são colocados em mercados locais.

A agricultura familiar apresenta uma elevada relação trabalho/terra: cria 87\% da ocupação total, dispondo de pouco mais de $40 \%$ da área total dedicada à agropecuária na MRH. Os sítios familiares geram ocupações que reproduzem a cultura material do lugar e sustentam a organização capilar que move essa sociedade. Este desempenho positivo da tradicional agricultura familiar não pode deixar de ser destacado quando se considera a baixa capacidade de geração de ocupações que existe no campo e na cidade brasileiros desde a década de 1980. 
Mas não é possível alimentar muitas ilusões sobre o tipo de ocupação que se cria. É preciso refletir, principalmente, sobre a qualidade da ocupação que é gerada: lembrar que esses dados se referem à ocupação feminina não-remunerada, ao trabalho masculino precário e em tempo parcial, ao trabalho infantil e, sobretudo, ao trabalho penoso que expõe trabalhadores de todas as idades e sexos a jornadas longas e inseguras. Percebe-se, assim, o caráter contraditório dessa agricultura familiar, pois à elevada capacidade de ocupar pessoal corresponde capacidade proporcionalmente menor de gerar renda, relação característica da baixa capitalização. Por conta disso, há décadas, muitos desses agricultores são obrigados a complementar rendas com a emigração sazonal, realizando um complexo redesenho dos territórios produtivos, re-elaborando-os em função das diferentes estacionalidades de demanda por força de trabalho: a entressafra da lavoura familiar do Jequitinhonha corresponde à safra da cana paulista ou do café do Sul de Minas.

Além de manter ocupações, a agricultura familiar internaliza na MRH um volume grande de recursos por área ocupada, originários das receitas de produção, aposentadorias e migrações. Isso pode ser lido de duas maneiras. Primeiro, na ótica da avaliação de programas de estímulo aos eucaliptais: percebe-se que o subsídio concedido às reflorestadoras pouco contribuiu para diversificar as origens e incrementar o volume de rendas. Segundo, na perspectiva micro-local: a centralidade da produção para comércio local e autoconsumo, a importância das aposentadorias rurais e das migrações revelam que as estratégias tradicionais da agricultura familiar foram mais competentes que o reflorestamento para adquirir e internalizar rendas, com menor custo social e melhor distribuição. Cada hectare ocupado por agricultores familiares representa mais renda que hectare de eucalipto; isso significa concretamente mais efeitos positivos sobre o comércio, maior produção para abastecimento local, maior diversificação em pequenos investimentos.

Os dados das Tabelas 6 e 8 indicam que não é possível fazer generalizações sobre os efeitos do progresso técnico na agricultura. As informações sobre silvicultura (Tabela 6) apontam que, neste caso, incentivos públicos, capitalização da atividade, estrutura empresarial e integração agroindustrial não foram suficientes para estimular o desenvolvimento da região. Apesar de dominar 38\% da área dedicada à agropecuária na $\mathrm{MRH}$, o eucalipto empregava apenas 4,08\% da força de trabalho, conseguindo apresentar índices relativos piores que os da pecuária tradicional, que ocupava 3,59\% dos trabalhadores com seus $16,24 \%$ de área de pastagens, segundo o Censo de 1995. Mesmo com a elevação excepcional de preços de carvão em 2000, o valor da produção por hectare de eucalipto permaneceu baixo em termos relativos: em 2005 a atividade gerou $\mathrm{R} \$ 410,35 \mathrm{em}$ VBP por hectare, receita muito inferior à média nacional da lavoura canavieira ( $R$ \$ 2.092,00/ha), da soja ( $R$ \$ 976,00/ha) e do milho ( $R$ \$ 1.026,00/ha). Ainda, este valor correspondia a menos de $40 \%$ do VBP por hectare da silvicultura do vale do 
rio Doce (Bacha e Barros, 2004; Agrianual, 2006). Isto, citando apenas atividades intensivas que demandam terras em abundância. $\mathrm{O}$ eucalipto também não apresenta bom resultado quando comparado ao VBP da agricultura familiar tradicional da região: usando dados das Tabelas 7 e 8, estimando redução de $14 \%$ na área ocupada, foram gerados $\mathrm{R} \$ 473,25$ por hectare; este valor é $15 \%$ superior àquele gerado pelos eucaliptais no ano de 2005, excepcionalmente rentável para o carvoejamento.

O desempenho medíocre da silvicultura em termos de ocupação de terra e pessoal revela que a privatização de recursos, concentração de capitais e intensificação produtiva aumentaram as dificuldades econômicas e sociais da região. Os recursos públicos investidos em eucalipto nos anos 1960/1980 geraram poucos e mal-pagos empregos - a média salarial das reflorestadoras é de 1,8 salários mínimos mensais -, e embora a silvicultura tenha contribuído para aumentar o número de empregados permanentes, este aumento foi pouco relevante. Mas, pela privatização dos recursos, do patrimônio e da terra, os eucaliptais contribuíram para introduzir na região o padrão nacional de concentração fundiária.

E esta é, exatamente, a questão mais explosiva. Os eucaliptais se estabeleceram em terras que nunca foram reconhecidas como pertencentes, por direito, às reflorestadoras: a tomada das chapadas comuns dos lavradores permanece sendo, na maior parte das comunidades rurais, uma chaga aberta, uma terra que os lavradores sentem ter sido expropriada do seu patrimônio.

Essa tomada de terras pode ser comparada com processo semelhante ocorrido no rio Doce, onde milhares de hectares de terras foram ocupados por eucaliptais com uso de métodos socialmente discutíveis. Mas a integração regional da produção e a expansão da economia urbano-industrial criaram empregos na região e estimularam a diversificação da economia regional. Assim, desde 1990, a questão agrária tendeu a perder expressividade na região, muito embora ainda esteja viva em alguns municípios. Por comparação, a insuficiência de resultados econômicos dos eucaliptais do Alto Jequitinhonha tende a alimentar conflitos sociais e fundiários, já presentes e, sobretudo, futuros.

É preciso considerar então que, no caso do Alto Jequitinhonha, os efeitos econômicos positivos da cadeia produtiva do carvão vegetal são, definitivamente, exportados para outras regiões: o pólo guseiro gera renda e empregos na região central de Minas Gerais, a siderurgia integrada transforma o Vale do Aço, a leste, em uma das economias regionais mais dinâmicas de Minas Gerais. A incapacidade desses reflorestamentos do Alto Jequitinhonha para criar ocupações, incrementar renda agrícola e estimular a integração econômica indica que, certamente, não é a atividade recomendada para estimular o desenvolvimento, nesta ou noutras regióes do mesmo perfil. Essa limitação se manifesta na persistência da estagnação da economia da MRH, na dependência perene das transferências dos programas públicos compensatórios, na permanência das emigrações sazonais e na elevada participação do Fundo de Participação dos Municípios na composição das receitas municipais. 


\section{Considerações finais}

A agricultura familiar tradicional do Jequitinhonha costuma ser apresentada como o mais completo exemplo do "atraso rural" nos estudos para o planejamento. É considerada pouco eficiente, pouco produtiva, mera atividade de subsistência com escassa influência no dinamismo econômico da região. Mas a sua capacidade de gerar ocupações, mesmo que precárias, e a possibilidade de conservar uma população expressiva na sua cultura solidamente enraizada em um território, servem como alertas para planejadores que cultivam ilusões sobre integração produtiva e privatização dos recursos naturais. Principalmente, servem de exemplo para formuladores de políticas que acreditam serem os grandes empreendimentos necessariamente inovadores. Para o desenvolvimento rural do Alto Jequitinhonha, conservar - por exemplo, as chapadas indivisas - certamente se revelaria melhor que inovar. Privatizá-las desenvolveu apenas o patrimônio de empresas, que receberam cerrados estimados em US\$ 38,00/hectare em 1975 e que podiam vendê-los a US\$ 380,00/hectare de terra nua em 2005.

A privatização de chapadas comuns beneficiou grandes empresas pela incorporação de renda da terra. As comunidades rurais arcaram com as perdas, da terra e de grande parte das condições tradicionais de reprodução. Além disso, receberam a conta dos passivos ambientais e sociais que a monocultura de eucaliptos direta e indiretamente acentuou: a erosão dos solos, a redução da água, a restrição das áreas de plantio e criação, a baixa renda e o duro ciclo da emigração sazonal. Três décadas depois se percebe que, em termos relativos, o cultivo de eucaliptos nas chapadas empobreceu mais os lavradores pobres da região.

Essas conclusões são importantes para compreender o vale do Jequitinhonha. É um lugar-como profetizava Saint-Hilaire-contraditoriamente definido pelas dimensões colossais das suas riquezas e dos seus problemas. Tem sido marcado nessas últimas três décadas pela dualidade entre a empresa que não emprega e a atividade familiar não capitalizada que sustenta parcialmente milhares de lavradores. Este caso é exemplar para refletir sobre políticas para o desenvolvimento rural e para sugerir alternativas ao modelo baseado na grande unidade de produção, que não se revelou nesta região um instrumento eficaz para combinar desenvolvimento, eqüidade e riqueza. 


\section{Referências Bibliográficas}

AGRIANUAL: Anuário da Agricultura Brasileira. São Paulo, Instituto FNP, 2006.

ASSOCIAÇAO MINEIRA DE SILVICULTURA - AMS. Preço médio do carvão.

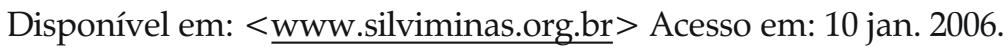

BACHA, C.J.C; BARROS, A.L.M. de. Reflorestamento no Brasil: evolução recente e perspectivas para o futuro. Scientia Florestalis. No. 66, dez/2004.

BORGES, M.H.; COLOMBAROLI, W. Carvão vegetal: opção energética para a siderurgia dos países tropicais. Florestal Acesita, 1978.

CALIXTO, J.S. Botica da natureza: conhecimento, uso e regulação de recursos vegetais para a saúde em comunidades rurais do Alto Jequitinhonha. Lavras, Monografia (Graduação Engenharia Florestal), Universidade Federal de Lavras, 2002.

CALIXTO, J. S. Reflorestamento, terra e trabalho: análise da ocupação fundiária e da força de trabalho no Alto Jequitinhonha, MG. Lavras, Dissertação (Mestrado), Universidade Federal de Lavras, 2006.

COUTINHO, C.S. Transferência de tecnologia e processo de trabalho na indústria siderúrgica. Belo Horizonte, Dissertação (mestrado), Cedeplar/UFMG, 1985.

DAYRELL, C.A. Geraizeiros e biodiversidade no Norte de Minas: a contribuição da agroecologia e da etnoecologia nos estudos dos agroecossistemas tradicionais. Dissertação (maestria) Universidade Internacional Andalucia. La Rábida, 1998.

ESTADO DE MINAS. "Deserdados da cana: usineiros mantêm esquema de recrutamento de pessoal baseado em agenciadores locais." Sexta-feira, 5 de maio de 2005.

FAO/INCRA. O novo retrato da agricultura familiar: o Brasil redescoberto. Disponível em http://www.incra.gov.br/index.php?visualiza=2938,711, acessado em 02032007.

FARIA, L.M. O carvão de madeira na siderurgia: um imperativo de segurança nacional. Mimeo., 1971. 
FUNDAÇÃO INSTITUTO BRASILEIRO DE GEOGRAFIA E ESTATÍSTICA. Censos agropecuários: 1970, 1980, 1985, 1996.

FUNDAÇAO SISTEMA ESTADUAL DE ANÁLISE DE DADOS. Força de trabalho na agricultura paulista. São Paulo: SEADE, 1996.

FURTADO, D.B. “Posseiros e despossuídos.” Belo Horizonte, Dissertação (MS) FAE/UFMG, 1985.

GALIZONI, F.M. "Terra, ambiente e herança no alto Jequitinhonha, MG". Revista de Economia e Sociologia Rural. 40(3) jul/set, 2002.

GASQUES, J.G.; CONCEIÇAO, J.C.P.R. A demanda de terra para a Reforma Agrária no Brasil. Seminário sobre reforma agrária e desenvolvimento sustentável, Anais... Fortaleza, 1998.

GRAZIANO, E. "A arte de viver na terra: as condições de reprodução camponesa no vale do Jequitinhonha." Itaguaí, Dissertação (Mestrado), Universidade Federal Rural do Rio de Janeiro, 1986.

INSTITUTO ESTADUAL DE FLORESTAS. Projeto de distritos florestais para Minas Gerais. Belo Horizonte,1975.

KOOPMANS, J. "Além do eucalipto: o papel do Extremo Sul" Cadernos do CEAS, Salvador, Abril/junho 2006, número 222.

LINHARES, M. Y.; TEIXEIRA DA SILVA, F. C. Terra prometida: uma historia da questão agrária no Brasil. Rio de Janeiro: Campus, 1999.

MDS - MINISTÉRIO DO DESENVOLVIMENTO SOCIAL E COMBATE Á FOME. Programas de transferência de renda. Disponível em: $<$ www.mds.gov.br $>$ Acesso em: 10 jan.2006.

MINAS GERAIS/Governo Rondon Pacheco. “Plano Mineiro de Desenvolvimento Econômico e Social. Belo Horizonte, Imprensa Oficial, 1971.

MOURA, M.M. Os deserdados da terra. Rio de Janeiro: Bertrand do Brasil, 1988.

NORONHA, A.G.B. “O tempo de ser, fazer e viver: modo de vida das populações rurais do Alto Jequitinhonha, MG." Lavras, dissertação (mestrado), PPGA/UFLA, 2003.

NUNES, M. A. Estruturação e reestruturações territoriais da região do Jequitinhonha em Minas Gerais. Belo Horizonte, Dissertação (Mestrado), UFMG, 2001. 
RIBEIRO, E.M. e GALIZONI, F.M. “Sistemas agrários, recursos naturais e migrações no alto Jequitinhonha, Minas Gerais." In Torres, H. e Costa, H. (orgs) População e meio ambiente: debates e desafios. São Paulo, Senac, 2000.

RIBEIRO, E. M.; CASTRO, B.S.; RIBEIRO, J.A. Feira livre de Minas Novas: Relatório Técnico. Lavras/Turmalina, 2004.

RIBEIRO, E.M.; GALIZONI, F.M.; CALIXTO, J.S.; ASSIS, T.P.; AYRES, E.B., SILVESTRE, L.H. Gestão, uso e conservação de recursos naturais em comunidades rurais do Jequitinhonha. Revista Brasileira de Estudos Urbanos e Regionais. Volume 7, número 2, novembro de 2005.

RIBEIRO, E.M.; ARAÚJO, D.P.; GALIZONI, F.M. “Uma estimativa preliminar das receitas monetárias e não-monetárias de agricultores familiares do vale do Jequitinhonha." IN ORTEGA, A.C. e ALMEIDA FILHO. Desenvolvimento territorial: segurança alimentar e economia solidária. Campinas, Alínea, 2007.

RIBEIRO, J.T.L. e CARVALHO, J.A.M. de. “A imigração para Minas Gerais no período 1981/1991, com enfoque na migração de retorno." Revista Brasileira de Estudos de População. V. 16 - n. 1/2 - jan/dez. 1999.

SAINT-HILAIRE, A. de. Viagem pelas províncias do Rio de Janeiro e Minas Gerais. Belo Horizonte/Itatiaia; São Paulo/Edusp, 1975.

THOMPSON, E. P. Costumes em comum: estudos sobre a cultura popular tradicional. São Paulo: Companhia das Letras, 1998.

VEIGA. J.E. da (coord). O Brasil rural precisa de uma estratégia de desenvolvimento. Brasília, Neagri/MDA, 2001. 